\title{
69
}

\section{Learner modelling by expert teachers: learner information space and the minimal learner model}

Anne McDougall

Monash University

Clayton

Australia

Roland Sussex

University of Queensland

Australia
Geoff Cumming

Samantha Cropp

La Trobe University

Bundoora

Australia

\begin{abstract}
Giving individualized guidance to a learner must rely on a learner model. Learner modelling has been little studied within education, although the specialised research field of Artificial Intelligence and Education (AI\&ED) has emphasized its importance. We present results from the Mayday project's observations of learning interactions suggesting that the learner models used by expert human teachers contain diverse kinds of information much of which is sketchy and conjectural. We propose a theoretical framework: the Learner Information Space and the Minimal Learner Model.
\end{abstract}

Main conference themes: learner centred learning, artificial intelligence

Educational areas: primary education, secondary education, higher education

Study topics:

Secondary keywords: cognition, knowledge representation, learning models, pedagogy, research 


\section{INTRODUCTION}

Individualization of guidance to a learner is the key to increasing the effectiveness of learning [1]. But individualized guidance must logically be based on some information about the individual learner. This information can be regarded as a model of the learner, a model which may be detailed and multifaceted or extremely sketchy and incomplete. In this paper we discuss the importance of learner modelling generally in education and report some initial investigations of the learner information which is used by expert teachers.

To give some everyday motivation for the notion of learner modelling, consider a common observation. An expert teacher walks around in a large class in which students are working individually or in groups. The teacher who has had little experience with this class, looks over a shoulder, pauses for a moment and then offers a comment. At most the teacher asks a brief question or two before commenting. The intervention is usually appropriate and valuable. The teacher may be drawing on great familiarity with the material and with common misconceptions, or with favoured ways to present some tricky point, yet the teacher chooses the comment specifically for that student or small group. Being able to make useful interventions in such circumstances is a striking and valuable aspect of teaching expertise.

What learner information shapes the teacher's intervention? Is the teacher using knowledge of an individual or applying a stereotype? When the teacher seeks a further small amount of information before commenting, what type of information is sought? These are important research questions; investigation of these and related questions concerning learner modelling are needed if we are to understand individualization in education.

\section{LEARNER MODELLING IN INTELLIGENT EDUCATIONAL SYSTEMS}

It is the research field of Artificial Intelligence and Education (AI\&ED) which has most consistently identified the importance of learner modelling. Development of learner models to be incorporated in Intelligent Educational Systems has been a central concern of the field. (We use the term Intelligent Educational System (IES) to refer broadly to any system having some relation with Artificial Intelligence and intended to promote learning; included are many tutoring systems, learning environments and microworlds.)

Recent work however has emphasized the deficiencies of past computational approaches to learner modelling and the difficulty of modelling beyond narrow artificial domains. For example Sleeman et al. [2] found a lack of clear educational effectiveness of the popular diagnose-bug-and-remediate 
approach and Putnam [3] found a lack of similarity between this diagnosis approach and human teaching. Despite including learner models and using computationally sophisticated formalisms and methodologies many IESs have seemed educationally naive and unnatural.

The response of some, e.g. Papert [4], to such difficulties was to emphasize a constructivist view of learning and the desirability of rich computer tools which encourage learner initiative. Such researchers-despite common misconceptions on this point-also emphasized the necessity for guidance: even from this perspective it is logically necessary that some kind of learner model must be used by a teacher and/or peer learners if any individual guidance is to be available.

A different response was offered by Cumming and Self [5]. They reaffirmed the need for learner modelling, but suggested strategies for making it more tractable. They saw a learner model as being open to the learner who could change it. It would be intended not as a detailed cognitive model, but as comprising information helpful in formulating advice to offer the learner who would be encouraged to regard the system as a fallible collaborator, rather than an all-knowing instructor. This change in attitude and revised conception of the computer's role were seen as crucial.

AI\&ED is steadily adopting such richer conceptions of learning. Most broadly the situated cognition position (see e.g. the whole issue 17 (1) of Cognitive Science) is becoming increasingly influential in AI\&ED. Meaning and intelligence are seen as emergent properties of a set of interactants in a context, rather than being inherent in any single entity. Similarly learning is seen as dependent on interactions in context and so the need is to study human learning and teaching in authentic settings.

The full implications for learner modelling of these radical changes in the approach being taken by many AI\&ED researchers have not yet been explored in detail. We regard detailed study of vital importance.

\section{LEARNER MODELLING IN THE DISCIPLINE OF EDUCATION}

Realisation of the importance of teacher knowledge of students is pervasive in education, although it is not often discussed sufficiently or studied explicitly. For example Dunkin and Biddle [6] included teachers' knowledge of properties of learners in their model for research on teaching under the broad headings of context and process variables, but did not identify it separately. Calderhead came closer in discussing typificatory and case knowledge which teachers have of learners, but again learner models held by teachers were not investigated in detail, although he identified the issue as vital for further research ([7], p. 274). 
Research on teachers' thought processes includes consideration of thoughts about learners, but the context is usually the classroom and the focus usually on how teachers respond to student behaviours, rather than the acquisition and use of knowledge about students' abilities and other characteristics.

In fact the research in education which comes closest to studying teacher knowledge of learners, is that most heavily influenced by cognitive science and AI\&ED, e.g. [3, 8]. Putnam, for example, studied individual tutoring and concluded that the comments of experienced teachers largely follow 'curriculum scripts' reflecting teachers' rich understanding of the domain and how to teach it, rather than being shaped in any detailed way by extensive knowledge of the individual learner. (Putnam's finding that the teacher uses only 'sparse' learner information foreshadowed some of our findings described below.) Brophy [9] brought together research studies supporting Putnam's conclusion and additionally identified the role of teacher knowledge of individual students as a currently contentious issue requiring detailed study.

Some research on teachers' thinking suggests that teachers use generalized, stereotype learner models to guide their interventions in the classroom and that expert teachers have well developed stereotypical models. Analysis of our own data also identifies cases in which the teacher seems to be drawing on stereotype information, for example that a student from a particular language background is likely to have some predictable problems in English. The respective roles of generalized and particular learner models remain to be investigated.

\section{EMPIRICAL STUDY OF LEARNING: THE TEACHER-LEARNER- COMPUTER TRIANGLE}

In the Mayday project three of us have studied the interactions of an expert teacher with a learner who is working at a computer. The domain is learning of English as a Second Language, specifically lexical learning. We developed software to support a wide range of activities designed to help learners develop their knowledge of words and how these are constructed [10].

We refer to the three-way interactions as the 'Teacher-Learner-Computer (TLC) Triangle' $[11,12]$. We note here in passing that it is remarkable that this Triangle arrangement has been very little studied. Two video cameras were used to record Triangle interactions and shortly after each session an audio recording was made of the teacher 'thinking aloud' while viewing selected portions of the video record. The main aim of Mayday is to study the various levels of interactions, but we have also become especially interested in what 
seems to be a central aspect of the teacher's expertise: the ability to use a small amount of learner information very effectively.

In the teacher interviews following Triangle sessions we ask the teacher specifically about what learner information was used in formulating comments to the learner. Our aim is to identify just what information about learners good teachers use.

\section{The learner models of expert teachers}

Detailed analyses made so far of transcriptions of the video and audio recordings lead us to some initial conclusions relating to learner modelling by teachers:

- Our Triangle arrangement is effective and practical, and offers a good approach for the study of learner modelling by expert teachers. Furthermore the teacher, while watching portions of the videos shortly after the Triangle session, is able to articulate goals and interpretations relevant to the formulation of teacher comments to the learner and to talk about learner information which had been used.

- A dialogue approach to the analysis of Triangle interactions is helpful. Many lengthy interaction sequences are too complex for full analysis. But shorter interaction sequences and sometimes the beginning of longer sequences can be fruitfully analyzed.

- We often observe that before a substantive comment is made the teacher will ask one or two brief questions aiming to find out some learner information This information is presumably judged by the teacher to be especially useful, and so is especially worthy of study. (For example a teacher described herself as "...trying to get a handle on where his problems were..." [Quotes are from teacher commentaries].)

- Teachers make use of a wide diversity of types of learner information. Information used may include cognitive, affective and social information; some will be short term and local, while some will relate to enduring aspects of that learner (" $[\mathrm{He}]$ is also a student who usually if he doesn't understand something will raise a fuss..." "Because she was quite comfortable last week with this kind of exercise." "...he leaves off the ends of words ... you hear him say it all the time, constantly when he is talking." "She's not fast, but she's pretty accurate.'). In addition stereotypes play some role (“...with a young fellow, er, maybe they like driving cars." "It's a typical Spanish mistake in that they spell the way they mispronounce the word." "Yes, I did [expect her to recognise the CIA], being from South America.").

- Teachers make use of fragmentary information: it is often very incomplete and they usually realize themselves it is incomplete. 
- Teachers sometimes use incorrect learner information and often make assumptions or guesses about a learner and interpretations of learner actions realizing that these might be wrong (“...he's in an upper intermediate class. So I would have expected that he'd have understood that but I was surprised that he really didn't seem to." "I didn't know how many crossword puzzles she had done before..." "I think that probably he had a pronunciation error in his head...").

The use by teachers of diverse, but incomplete and conjectural learner information emphazises an important contrast between human teaching and learning, and the approach of AI\&ED. Almost all learner modelling so far in IESs has concerned a single type of learner information (e.g. current cognitive ability or knowledge, at a certain grain size, in the chosen learning domain) and has attempted a more-or-less complete representation of that information. Our Triangle studies suggest that the first aspect (restriction to a single type of information) may be a major weakness, while the second (attempt at completeness) may be unnecessary. However, it is a major challenge to identify just what information can be omitted.

\section{THE MINIMAL LEARNER MODEL}

Our working conclusion is that expert teachers can give effective guidance to individual learners despite having rather little information about them. In formulating comments to a learner the expert teacher seems to be able to use a small amount of information about that learner extremely effectively. We refer to the learner information that is most potent for shaping teacher comments as constituting the Minimal Learner Model, or MLM.

Being able to describe the MLM would be theoretically important and practically valuable for both education and AI\&ED. Might teachers do better in education if they have insight into their learner models and how minimal may these models be? Could this insight guide teachers in choosing which small amount of extra learner information to elicit before formulating an intervention? There would certainly be implications for teacher professional development.

\section{Formalized learner models}

To be incorporated into an IES a learner model must be expressed in computational form. This stringent requirement is one reason for the perceived educational narrowness of many existing systems. Discovering how teaching interventions can be effectively made with only incomplete knowledge of the learner has the potential to inform the development of future IESs which can 
support richer learning, but the eventual need to formalize learner information cannot be escaped. If the small amount of learner information that is likely to be of most educational value could be specified, the development of the learner model within an IES might become more tractable and the learning experience offered may become more natural.

But if it is indeed an essential feature of the Minimal Learner Model that it comprises a diversity of types of learner information, the difficulty of building the corresponding computational learner model may in some ways even be increased.

\section{The learner information space}

As a starting point for characterizing teachers' learner models we are developing a theoretical framework for Minimal Learner Models. Many types of information could have a place in a learner model. If we had a full multidimensional characterization of every conceivable aspect of humans we could use the dimensions to describe any learner model. Lacking such a full description we consider a partial framework.

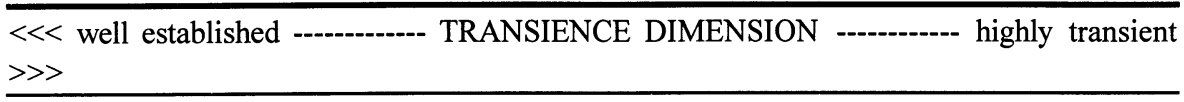

\begin{tabular}{|c|c|c|c|c|c|c|c|}
\hline $\begin{array}{l}\text { Temperament } \\
\text { (introvert) } \quad \ldots\end{array}$ & $\cdots$ & $\ldots$ & & I today) & $\ldots$ & $\cdots$ & (momentarily interested) \\
\hline $\begin{array}{l}\text { Cognitive style } \\
\text { (visual, holistic) }\end{array}$ & $\ldots$ & $\ldots$ & $\ldots$ & $\ldots$ & $\cdots$ & $\ldots$ & (want to see a diagram) \\
\hline $\begin{array}{l}\text { Language } \\
\text { (Mother Tongue: Eng }\end{array}$ & lish) ... & $\cdots$ & $\cdots$ & $\cdots$ & $\cdots$ & $\cdots$ & (note a new spelling) \\
\hline $\begin{array}{l}\text { Performance ability } \\
\text { (ride a bicycle)... }\end{array}$ & $\ldots$ & $\ldots$ & \multicolumn{4}{|c|}{ (use computer mouse) ... } & $\begin{array}{l}\text { (note stretch to the @ } \\
\text { key) }\end{array}$ \\
\hline $\begin{array}{l}\text { Maths declarative kno } \\
(2+2=4) \quad \ldots\end{array}$ & $\begin{array}{l}\text { wledge } \\
\ldots\end{array}$ & $\cdots$ & $\cdots$ & $\cdots$ & $\cdots$ & $\cdots$ & $\begin{array}{l}\text { (have just used calculator } \\
\text { to find } \sin 45-=0.7071 \text { ) }\end{array}$ \\
\hline $\begin{array}{l}\text { Physical abilities } \\
\text { (hand grip is strong).. }\end{array}$ & & $\ldots$ & $\ldots$ & $\ldots$ & $\ldots$ & $\ldots$ & (pins and needles in arm) \\
\hline
\end{tabular}

Fig. 1. The Learner Information Space, showing the transience dimension on several human characteristics. Example values are given in parentheses. 
A learner model could contain information about, for example, personality, various abilities and knowledge, past experience, feelings, preferences and recent actions. One dimension of obvious importance loosely combines: grain size of information, ease of modification, length of time since acquisition and time of likely persistence. At one end (the left in Figure 1) is information in large, well-established pieces, probably resistant to change. On the right are recently encountered, not-yet-consolidated fragments. We refer to this as the Transience dimension. We refer to the full potential array as the Learner Information Space (LIS).

Any individual at a particular time could be described by a set of terms or values in the LIS. Terms at the left would remain stable, while terms at the right might change frequently. The Minimal Learner Model would be the small subset which suffices to support good interventions for that learner at that time. We suspect that a Minimal Learner Model will include information from the left hand end of some characteristics, plus right hand end information on a few characteristics. The latter would correspond to noting recent activity and its outcome. Large areas of the whole array may be simply absent from the Minimal Learner Model.

\section{CONCLUSIONS}

A closer research link between education and AI\&ED has great potential: education (and more recently situated cognition) offers a rich conception of learning and ways to study learning in authentic settings, while AI\&ED emphazises the modelling of individual learners and the necessity of detailed descriptions of teachers' learner models. In education a combined approach may lead to theories of teaching which include a developed account of learner models and practical advice to teachers about effective use of learner information. In AI\&ED it might lead to learner models appropriate for IESs which can support rich learning.

Our Mayday analyses lead us to the initial conclusions that expert teachers use learner information which is highly diverse, very incomplete and scanty, and conjectural and often mistaken. They manage, however, to use this learner information with great effectiveness. If we can identify and describe the information in Minimal Learning Models both education and AI\&ED should benefit substantially, as should individualization in education. 


\section{ACKNOWLEDGEMENTS}

Tony Gedge created the MAYDAY software. The MAYDAY project was supported by the Australian Research Council (Grant No. AC9031953) and by Apple Australia.

\section{REFERENCES}

1. Bloom, B. S. (1984) The 2 sigma problem: The search for methods of group instruction as effective as one-to-one tutoring. Educational Researcher, 13, pp. 4-16.

2. Sleeman, D., Ward, R. D., Kelly, E., Martinak, R. and Moore, J. (1991) An overview of recent studies with PIXIE. In Goodyear, P. (ed.), Teaching knowledge and intelligent tutoring. Norwood, N.J.: Ablex, pp. 173-185.

3. Putnam, R. T. (1987) Structuring and adjusting content for students: A study of live and simulated tutoring of addition. American Educational Research Journal, 24, pp. 13-48.

4. Papert, S. (1980) Mindstorms: Children, computers, and powerful ideas. New York: Basic Books.

5. Cumming, G. and Self, J. (1991) Learner modelling in collaborative intelligent educational systems. In Goodyear, P. (ed.), Teaching knowledge and intelligent tutoring. Norwood, N.J.: Ablex, pp. 85-104.

6. Dunkin, M., and Biddle, B. (1974) The study of teaching. New York: Holt Rinehart \& Winston.

7. Calderhead, J. (1991) Representations of teachers' knowledge. In Goodyear, P. (ed.), Teaching knowledge and intelligent tutoring (pp. 269-278). Norwood, N.J.: Ablex.

8. Leinhardt, G. and Greeno, J. G. (1986) The cognitive skill of teaching. Journal of Educational Psychology, 78, pp. 75-95.

9. Brophy, J. (1991) Advances in research on teaching, Vol. 2: Teachers' knowledge of subject matter as it relates to their teaching practice. Greenwich, Conn.: JAI Press. 
10. Sussex, R., Cumming, G. and Cropp, S. (1994) A tools-based environment for discovery-oriented CALL: Cognitive, pedagogical and ergonomic issues for interactive learning. Computer-Assisted Language Learning Journal, 7, pp. 133-149.

11. Cumming, G., Sussex, R. and Cropp, S. (1993) The Teacher-LearnerComputer Triangle for the situated observation of learning. In Brna, P., Ohlsson, S. and Pain, H. (eds.), Artificial intelligence in education, Proceedings of the International Conference on Artificial Intelligence and Education 1993, Edinburgh, August. (p. 549) Charlottesville, VA: Association for the Advancement of Computing in Education.

12. Cumming, G., Sussex, R. and Cropp, S. (1994) The Teacher-LearnerComputer triangle in CALL: Frameworks for interaction and advice. Computer-Assisted Language Learning Journal, 7, pp. 107-123. 